\title{
Study of Intravenous Ferric Carboxymaltose in Iron Deficiency Anemia in Women attending Gynecological Clinic: Safety and Efficacy
}

\author{
${ }^{1}$ Vineet Mishra, ${ }^{2}$ Priyankur Roy, ${ }^{3}$ Khushali Gandhi, ${ }^{4}$ Shaheen Hokabaj, ${ }^{5}$ Rohina Aggarwal
}

\begin{abstract}
Introduction: Several intravenous iron preparations are available for the treatment of iron deficiency anemia (IDA). Some of these require multiple small infusions to prevent labile iron reactions, while iron dextran (DEX) is associated with a risk of potentially serious anaphylactic reactions. Ferric carboxymaltose (FCM), a non-DEX intravenous iron, is an effective and a safe option, which can be administered in high single doses without serious adverse effects.
\end{abstract}

Objective: The objective of the study was to evaluate the efficacy and safety of FCM in the treatment of IDA in gynecological patients.

Materials and methods: It was an open, single-arm study including 442 women of age more than 18 years with definitive diagnosis of IDA and hemoglobin $(\mathrm{Hb})$ between 4 and $11 \mathrm{gm} \%$ from December 2013 to November 2016. Out of these, 25 women were lost to follow-up and were excluded from the study. Intravenous FCM (500-1500 mg) was administered and the improvement in $\mathrm{Hb}$ levels and iron stores was assessed after 3 weeks of total dose infusion.

Results: Out of the 442 women, 417 women were included in the analysis. Most of the women were in the age group of 30 to 39 years. Most of the women had mild anemia as per the World Health Organization (WHO) guidelines. Mean Hb levels significantly increased over a period of 3 weeks after FCM administration. Other parameters like total iron-binding capacity (TIBC), ferritin, and iron also had a significant improvement after FCM administration. No serious life-threatening adverse events were observed after FCM administration.

Conclusion: Intravenous FCM is an effective and a safe treatment option for IDA and has an advantage of single administration of high doses without serious adverse effects.

Keywords: Ferric carboxymaltose, Hemoglobin, Iron deficiency anemia.

How to cite this article: Mishra V, Roy P, Gandhi K, Hokabaj S, Aggarwal R. Study of Intravenous Ferric Carboxymaltose in Iron Deficiency Anemia in Women attending Gynecological

\footnotetext{
${ }^{1}$ Professor and Head, ${ }^{2}$ Senior Resident, ${ }^{3}$ Assistant Professor ${ }^{4}$ Fellow, ${ }^{5}$ Professor

1,3-5 Department of Obstetrics and Gynecology, Institute of Kidney Diseases and Research Center, Ahmedabad, Gujarat, India

${ }^{2}$ Department of Obstetrics and Gynecology, North Bengal Medical College, Siliguri, West Bengal, India

Corresponding Author: Vineet Mishra, Professor and Head Department of Obstetrics and Gynecology, Institute of Kidney Diseases and Research Center, Ahmedabad, Gujarat, India e-mail: vineet.mishra.ikdrc@gmail.com
}

Clinic: Safety and Efficacy. J South Asian Feder Menopause Soc 2017;5(2):71-74.

Source of support: Nil

Conflict of interest: None

Date of received: 13 July 2017

Date of acceptance: 24 September 2017

Date of publication: December 2017

\section{INTRODUCTION}

Iron deficiency is recognized as a common nutritional deficiency among women of childbearing age in both the developed and developing world. Iron deficiency may lead to fatigue, cardiorespiratory problems, increased chances of infection, reduced immunity, depressive episodes and also predisposes women to the adverse effects of blood transfusion.

The IDA can be treated by both oral and parenteral routes. Oral iron is the preferred route for initial treatment. However, oral iron supplementation often leads to side effects, such as nausea, vomiting, constipation, and abdominal pain leading to poor compliance and a poor response to the therapy. ${ }^{1}$ In addition, chronic inflammatory conditions may cause poor absorption of iron. Oral iron preparations are also not appropriate for treatment of severe anemia where rapid replenishment of iron stores is required. ${ }^{2}$

Various intravenous iron preparations are available for the treatment of IDA. Iron DEX is associated with a potential risk of serious anaphylactic reactions, while others need to be given in multiple infusions. The FCM was approved by the US Food and Drug Administration in July 2013 for the treatment of IDA. The FCM can be administered directly over 7 to 8 minutes or diluted in saline for infusion. The ability to safely inject a single dose as large as $1500 \mathrm{mg}$ in as little as 15 minutes and, thereby, reduce the need for multiple infusions render FCM an ideal drug for the treatment of IDA.

Side effects are rare, but may occur and are usually mild like nausea; vomiting; pain; discolored skin at the site of injection; flushing (warmth, redness, or tingly feeling); and increased blood pressure with headache or dizziness. The management is only symptomatic and no other interventions are usually required. 


\begin{tabular}{ll}
\hline & Table 1: Distribution according to age \\
\hline Age (years) & No. of women $(n=417)$ \\
\hline $20-29$ & $102(24.46 \%)$ \\
$30-39$ & $159(38.12 \%)$ \\
$40-49$ & $147(35.26 \%)$ \\
$50-70$ & $9(2.16 \%)$ \\
\hline
\end{tabular}

\section{MATERIALS AND METHODS}

This was an observational study conducted over a period of 3 years (December 2013 to November 2016). A total of 442 women attending the Gynecology Clinic at the Institute of Kidney Disease and Research Centre, Ahmedabad, India, were recruited for the study.

\section{Study Outcome}

The primary aim was to study the efficacy and safety of FCM in the treatment of IDA in gynecological patients.

\section{Study Design}

Observational study.

\section{Study Period}

December 1, 2013 to November 30, 2016.

\section{Informed Consent}

After explaining the requirement of administering FCM and its adverse effects, written informed consent were obtained from all the patients and attenders.

\section{Inclusion Criteria}

- Women more than 18 years of age, with a definitive diagnosis of IDA.

- $\mathrm{Hb}$ levels between 4 and $11 \mathrm{gm} \%$.

\section{Exclusion Criteria}

- Previous allergic reactions to iron therapy

- Pregnant women

- Anemia due to other causes

- Women with hemodynamic instability

Iron deficiency was diagnosed on parameters like complete blood count, peripheral blood smear, packed cell volume (PCV), serum ferritin, serum TIBC, and serum iron. Patients were explained about the drug and possible side effects. About 25 women were lost to follow-up and were excluded from the analytics of the study.

The total required dose of FCM was calculated based on $\mathrm{Hb}$ deficit and body weight using Ganzoni formula:

Total iron deficit $(\mathrm{mg})=$ Body weight $(\mathrm{kg}) \times[$ Target $\mathrm{Hb}-$ Actual $\mathrm{Hb}(\mathrm{gm} \%)] \times 0.24+$ Depot iron $(\mathrm{mg})$

Depot iron $=15 \mathrm{mg} / \mathrm{kg}$ in case of body weight $<35 \mathrm{~kg}$ and $500 \mathrm{mg}$ in case of weight $>35 \mathrm{~kg}$

Table 2: Distribution according to degree of anemia (WHO classification)

\begin{tabular}{ll}
\hline Degree of anemia & No. of women $(n=417)$ \\
\hline Mild & $309(74.10 \%)$ \\
Moderate & $108(25.90 \%)$ \\
Severe & 0 \\
\hline
\end{tabular}

A single dose of FCM should not exceed $1000 \mathrm{mg}$ of iron $(20 \mathrm{~mL})$ per day. Not more than $1000 \mathrm{mg}$ of iron was administered in a week. The FCM was administered as an infusion diluted in sterile $0.9 \%$ sodium chloride $(\mathrm{NaCl})$ solution. The FCM injection $500 \mathrm{mg}$ can be diluted with $100 \mathrm{~mL} \mathrm{NaCl}$ and administered over 6 minutes. Doses between 1000 and $1500 \mathrm{mg}$ require dilution with $250 \mathrm{~mL}$ $\mathrm{NaCl}$ and an administration time of 15 minutes. The drug was administered under direct supervision, and infusion was immediately stopped in case of any side effects. The patients were followed up after 3 weeks of total dose infusion to assess the status of iron stores and increase in $\mathrm{Hb}$ using the same parameters as previously mentioned.

\section{RESULTS}

A total of 442 women were included in the study and 25 women were lost to follow-up; hence, 417 women were included for the analytics of the study. Age-specific distribution of patients is shown in Table 1. The majority of women were in the age group of 30 to 39 years (38.12\%). Distribution of all subjects according to WHO classification of degree of anemia is depicted in Table 2. Most of the patients $(74.10 \%)$ had mild anemia, while moderate anemia was present in $25.89 \%$ cases. None of the patients had severe anemia.

As calculated according to Ganzoni formula, $17.98 \%$ women required 1 vial of FCM, $57.55 \%$ women required 2 vials of FCM, whereas 3 vials of FCM were required in $24.47 \%$ women for total infusion (Table 3). No serious life-threatening adverse events were reported in any of the women. Totally, 12 women had local reactions like itching and irritation at local sites and another 15 women reported systemic reactions in the form of giddiness, headache, and nausea (Table 4).

These women presented to us with various ailments and required varied treatment modalities, which are illustrated in Table 5. There was a significant improvement in $\mathrm{Hb}$ levels over a period of 3 weeks from mean $\mathrm{Hb}$ of $8.70 \pm 1.04$ to $11.07 \pm 1.02$. Other parameters like TIBC, ferritin, and iron also suggested a significant improvement

Table 3: Number of FCM vials administered

\begin{tabular}{llll}
\hline No. of vials & 1 & 2 & 3 \\
\hline $\begin{array}{l}\text { No. of women } \\
(n=417)\end{array}$ & $75(17.98 \%)$ & $240(57.55 \%)$ & $102(24.47 \%)$ \\
\hline
\end{tabular}


Study of Intravenous Ferric Carboxymaltose in Iron Deficiency Anemia

Table 4: Adverse reactions of FCM

\begin{tabular}{ll}
\hline Description & No. of women $(n=417)$ \\
\hline Local reactions & $12(2.87 \%)$ \\
Systemic reactions & $15(3.59 \%)$ \\
Total adverse reactions & $27(6.46 \%)$ \\
\hline
\end{tabular}

Table 6: Laboratory parameters before and after FCM administration

\begin{tabular}{lllr}
\hline Variables & Prevalues & Postvalues & $p$-value \\
\hline $\mathrm{Hb}(\mathrm{gm} \%)$ & $8.70 \pm 1.04$ & $11.07 \pm 1.02$ & $<0.00$ \\
$\mathrm{PCV}$ & $31.44 \pm 29.82$ & $36.23 \pm 2.38$ & 0.06 \\
$\mathrm{TIBC}$ & $353.84 \pm 107.12$ & $275.15 \pm 208.93$ & $<0.00$ \\
Ferritin & $23.76 \pm 58.88$ & $99.77 \pm 31.53$ & $<0.00$ \\
Iron & $39.43 \pm 20.17$ & $85.81 \pm 26.04$ & $<0.00$ \\
Reticulocyte count & $0.96 \pm 0.53$ & $0.96 \pm 0.17$ & 0.91 \\
\hline
\end{tabular}

after FCM administration. The sense of wellbeing also improved in all patients on follow-up. Table 6 shows the efficacy of the drug in the management of IDA in our study population.

\section{DISCUSSION}

The IDA occurs due to various reasons, such as abnormal uterine bleeding, inflammatory bowel disease, postpartum IDA, or chronic renal disease. The FCM is a novel ferric hydroxide carbohydrate complex, which when administered intravenously is effective in its treatment. It provides controlled delivery of iron to target tissues with a minimal risk of release of large amounts of ionic iron in the serum, and, thus, prevents adverse events seen with other iron preparations. ${ }^{3}$ One of the earliest intravenous iron preparations containing DEX was associated with the risk of serious allergic or anaphylactic reactions. ${ }^{4}$ Subsequent iron preparations, such as iron sucrose or ferric gluconate resulted in fewer hypersensitivity reactions, but the iron-carbohydrate complex was less stable with a risk of toxic reactions to nontransferrin-bound iron. So, large doses could not be administered at a time and multiple infusions were required. ${ }^{4}$ The FCM has a more stable structure as compared with iron sucrose and ferric gluconate. Therefore, large doses can be administered over shorter periods resulting in rapid replenishment of iron stores with fewer administrations. ${ }^{5,6}$

Bregman et $\mathrm{al}^{7}{ }^{7}$ Evstatiev et $\mathrm{al}^{8}{ }^{8}$ and Hussain et $\mathrm{al}^{9}$ proved that FCM was well tolerated and had better compliance than other iron preparations. The results of our study were consistent with the above-mentioned trials. The FCM has been shown to be an effective option in the treatment of IDA in multiple studies, and it also improves the quality of life. ${ }^{10,11}$ There was an increase in mean $\mathrm{Hb}$ levels with replenishment of iron stores and clinical improvement after FCM administration. The FCM
Table 5: Gynecological condition associated in all women

\begin{tabular}{ll}
\hline Associated conditions & No. of women $(n=417)$ \\
\hline Open surgery & $231(55.40 \%)$ \\
Diagnostic and operative & $123(29.50 \%)$ \\
hysterolaparoscopy & \\
Laparoscopic hysterectomy & $51(12.22 \%)$ \\
Vaginal hysterectomy & $6(1.44 \%)$ \\
In vitro fertilization treatment & $6(1.44 \%)$ \\
\hline
\end{tabular}

was well tolerated and was associated with few local and mild systemic reactions, but no serious life-threatening allergic reactions were reported. Thus, FCM is a safe and an effective treatment option for IDA. ${ }^{12}$

Most of the studies have shown that FCM is relatively safe with a low incidence of adverse effects. Most common adverse effects noted were nausea, diarrhea, bloating, abdominal pain, headache, and rashes. ${ }^{13}$ Serious adverse reactions noted were unrelated to FCM administration. ${ }^{14}$ These findings were similar to our study.

\section{CONCLUSION}

The FCM is a safe and an effective treatment option for IDA of various etiologies in patients who are noncompliant or unresponsive to oral iron or where oral iron is not suitable for treatment as in cases of severe anemia, where rapid correction as well as replenishment of iron stores are required.

\section{REFERENCES}

1. Killip S, Bennett JM, Chambers MD. Iron deficiency anemia. Am Fam Physician 2007 Mar;75(5):671-678.

2. Silverstein SB, Gilreath JA, Rodgers GM. Intravenous iron therapy: a summary of treatment options and review of guidelines. J Pharm Pract 2008 Sep;21(6):431-43.

3. Lyseng-Williamson KA, Keating GM. Ferric carboxymaltose: a review of its use in iron-deficiency anemia. Drugs 2009 Jan;69(6):739-756.

4. Qunibi WY. The efficacy and safety of current intravenous iron preparations for the management of iron-deficiency anemia: a review. Arzneimittelforschung 2010 Jan;60(6a):399-412.

5. Van Wyck DB, Martens MG, Seid MH, Baker JB, Mangione A. Intravenous ferric carboxy maltose compared with oral iron in the treatment of postpartum anemia: a randomized controlled trial. Obstet Gynecol 2007 Aug;110(2):267-278.

6. Van Wyck DB, Mangione A, Morrison J, Hadley PE, Jehle JA, Goodnough LT. Large-dose intravenous ferric carboxy maltose injection for iron deficiency anemia in heavy uterine bleeding: a randomized, controlled trial. Transfusion 2009 Dec;49(12):2719-2728.

7. Bregman DB, Goodnough LT. Experience with intravenous ferric carboxy maltose in patients with iron deficiency anemia. Ther Adv Hematol 2014 Apr;5(2):48-60.

8. Evstatiev R, Marteau P, Iqbal T, Khalif IL, Stein J, Bokemeyer B, Chopey IV, Gutzwiller FS, Riopel L, Gasche C, FERGI Study Group. FERGIcor, a randomized controlled trial on ferric carboxymaltose for iron deficiency anemia in inflammatory bowel disease. Gastroenterology 2011 Sep;141(3):846-853. 
9. Hussain I, Bhoyroo J, Butcher A, Koch TA, He A, Bregman DB. Direct comparison of the safety and efficacy of ferric carboxy maltose versus iron dextran in patients with iron deficiency anemia. Anemia 2013 Aug;2013:169107.

10. Barish CF, Koch T, Butcher A, Morris D, Bregman DB. Safety and efficacy of intravenous ferric carboxy maltose (750 mg) in the treatment of iron deficiency anemia: two randomized, controlled trials. Anemia 2012 Jun;2012:172104.

11. Charytan C, Bernardo M, Koch TA, Butcher A, Morris D, Bregman DB. Intravenous ferric carboxy maltose versus standard medical care in the treatment of iron deficiency anemia in patients with chronic kidney disease: a randomized, active-controlled, multicenter study. Nephrol Dial Transplant 2013 Apr;28(4):953-964.
12. Wolf M, Koch TA, Bregman DB. Effects of iron deficiency anemia and its treatment on fibroblast growth factor 23 and phosphate homeostasis in women. J Bone Miner Res 2013 Aug;28(8):1793-1803.

13. Anker SD, Colet JC, Filippatos G, Willenheimer R, Dickstein $K$, Drexler H, Lüscher TF, Bart B, Banasiak W, Niegowska J, et al. Ferric carboxy maltose in patients with heart failure and iron deficiency. N Engl J Med 2009 Dec;361(25):2436-2448.

14. Kulnigg S, Stoinov S, Simanenkov V, Dudar LV, Karnafel W, Garcia LC, Sambuelli AM, D'Haens G, Gasche C. A novel intravenous iron formulation for treatment of anemia in inflammatory bowel disease: the ferric carboxy maltose (FERINJECT): a randomized controlled trial. Am J Gastroenterol 2008 May;103(5):1182-1192. 